\title{
Cardiovascular Disease in Ankylosing Spondylitis: Another Extra-Skeletal Feature of a Chronic Inflammatory Disorder?
}

\section{Alexandros A Drosos* and Charalampos Papagoras}

Department of Internal Medicine, Medical School, University of loannina, Ioannina, Greece

Ankylosing spondylitis (AS) is a chronic idiopathic inflammatory disease primarily affecting the skeleton [1]. The hallmark of skeletal involvement is axial disease, which is characterized by inflammation of the sacroiliac joints and spinal structures, such as ligaments, intervertebral discs, zygoapophyseal joints and vertebral bodies [2,3]. The whole process progresses through bone marrow edema, pannus formation, erosive changes of osseous and cartilaginous structures and finally new bone deposition leading to bony ankylosis and syndesmophyte formation [4]. Additional skeletal manifestations may be enthesitis (an almost pathognomonic feature of the spondyloarthritides) and peripheral asymmetric oligoarthritis $[2,5]$.

Apart from musculoskeletal structures, several other tissues and organs may be involved in the course of AS. Indeed, inflammation may affect the uvea, with the occurrence of acute anterior uveitis, the skin, with the appearance of psoriasis, or the gut, which may be inflamed either subclinically or overtly in the form of ulcerative colitis or Crohn's disease [6-8]. It is also established that in a proportion of AS patients, certain parts of the heart and the aorta may be affected [9], possibly as a result of an inflammatory process directed against fibrocartilage present in the central fibrous body of the heart or the arterial wall. Pathologically, inflammation and scarring may be observed in the aortic root, giving rise to aortic regurgitation, whereas involvement of the adjacent heart conduction system may result in various types of conduction abnormalities, up to complete heart block [10,11]. This type of heart involvement seems to be AS-specific both on morphological and genetic grounds. Indeed, a combination of aortic regurgitation and severe conduction abnormalities has been closely associated with HLA B27 positivity, the major genetic marker related to AS $[12,13]$.

Although aortic valve disease and conduction disturbances have been reported in up to $10 \%$ and $9 \%$ of AS patients respectively [9], their impact on the overall morbidity and mortality of AS remains uncertain. In an electrocardiographic study of 131 AS patients, the most common abnormality was prolonged QRS interval $(29.2 \%)$, but no cases of high-grade atrioventricular block were identified [14]. Moreover, in an analysis of the causes of death in a cohort of 398 AS patients, the leading cause of death was diseases of the circulatory system accounting for 64 out of 152 or $42.1 \%$ of recorded deaths. Compared to the general population, there was a surplus of 11 cardiovascular deaths with a corresponding standardized mortality ratio (SMR) due to cardiovascular causes of 1.2. It should be noted that in that study only 6 deaths $(3.9 \%)$ were attributed to AS-specific heart disease, which were classified separately from the 64 deaths due to circulatory diseases [15]. Indeed, cardiovascular disease has been confirmed by plenty of other studies to be the most frequent cause of death in AS patients [16], while some authors have asserted that cardiovascular disease may proportionately claim more lives among AS patients than in the general population [17]. Moreover, several studies, employing a wide range of methodologies have demonstrated that AS patients are at significantly greater risk for ischemic heart disease $[6,18,19]$, for myocardial infarction [20], for early coronary revascularization procedures [21], for cerebrovascular disease $[18,19]$, as well as for peripheral vascular disease $[18]$ and heart failure $[18,19]$ (Table 1).

Despite variations in study design and occasionally conflicting results (for example as regards the risk for myocardial infarction), the overall conclusion drawn from the aforementioned studies is that there seems to be an excess atherosclerotic cardiovascular disease in AS, manifesting as ischemic heart disease, cerebrovascular or peripheral arterial disease. Such a conclusion, though, should not appear irrelevant given the wealth of evidence supporting an increased risk for cardiovascular disease in patients with rheumatoid arthritis (RA) as well [18,22-24]. However, how could such an excess cardiovascular risk in AS be explained? According to the RA paradigm, three potential interpretations might be suggested [25]: that AS treatment has a negative impact on the cardiovascular risk; that classic cardiovascular risk factors are more prevalent in AS patients; or that AS-related systemic inflammation contributes independently to the atherosclerotic process.

For decades, the mainstay of AS treatment have been the nonsteroidal anti-inflammatory drugs (NSAIDs), a drug class that has recently been associated with adverse cardiovascular events [26]. However, a study of patients with inflammatory polyarthritis taking NSAIDs failed to demonstrate an elevated rate of cardiovascular deaths

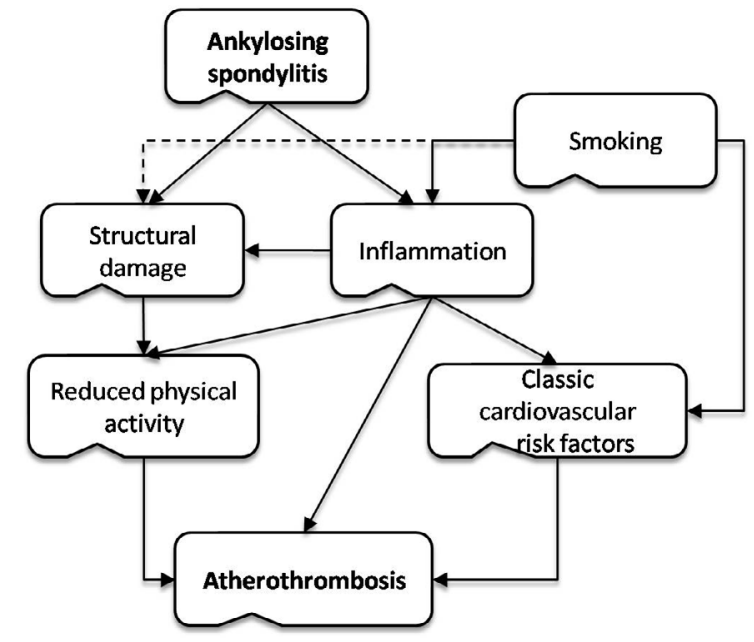

Figure 1: A schematic representation of the cross-talk between AS-related inflammation, the classical cardiovascular risk factors and the process of atherothrombosis as has been shaped by the results of several studies on AS patients and by analogies with another chronic inflammatory joint disease, rheumatoid arthritis. The dashed arrow denotes a statistical association that merits further elucidation.

*Corresponding author: Alexandros A Drosos, Professor of Medicine/ Rheumatology, Rheumatology Clinic, Department of Internal Medicine, Medical School, University of Ioannina, 45110, Ioannina, Greece, Tel: +30 2651007503 Fax: +30 26510 07054; E-mail: adrosos@cc.uoi.gr

Received October 10, 2012; Accepted October 11, 2012; Published October 13 2012

Citation: Drosos AA, Papagoras C (2012) Cardiovascular Disease in Ankylosing Spondylitis: Another Extra-Skeletal Feature of a Chronic Inflammatory Disorder? J Spine 1:e106. doi:10.4172/2165-7939.1000e106

Copyright: (c) 2012 Drosos AA, et al. This is an open-access article distributed under the terms of the Creative Commons Attribution License, which permits unrestricted use, distribution, and reproduction in any medium, provided the original author and source are credited. 


\begin{tabular}{|c|c|c|c|}
\hline Author, Year [Ref] & $\begin{array}{l}\text { Study design } \\
\text { (Country) }\end{array}$ & $\begin{array}{l}\text { Number of } \\
\text { patients }\end{array}$ & Results \\
\hline Han, 2006 [18] & $\begin{array}{l}\text { Medical database } \\
\text { analysis (USA) }\end{array}$ & 1843 & $\begin{array}{cl}\text { Prevalence ratio (lower-upper CI) } \\
\text { - } \quad \text { IHD: } 1.2(1-1.5) \\
\text { - } \quad \text { CHF: } 1.8(1.2-2.6) \\
\text { - } \quad \text { PVD: } 1.7(1.3-2.3) \\
\text { - } \quad \text { Hypertension: } 1.3(1.1-1.4) \\
\text { - } \quad \text { Type 2 DM: } 1.2(1-1.4) \\
\text { - Hyperlipidemia: } 1.2(1.1-1.3)\end{array}$ \\
\hline Peters, 2010 [20] & $\begin{array}{l}\text { Mail survey } \\
\text { (The Netherlands) }\end{array}$ & 383 & Odds ratio $(95 \% \mathrm{Cl})$ for MI $3.1(1.9-5.1)$ \\
\hline Szabo, 2011 [19] & Administrative database analysis (Canada) & 8616 & $\begin{array}{cc}\text { Standardized prevalence ratios }(95 \% \mathrm{CI}) \\
\bullet \quad \text { IHD: } 1.37(1.31-1.44) \\
\bullet \quad \text { CHF: } 1.34(1.26-1.42) \\
\bullet \quad \text { CVD: } 1.25(1.15-1.35)\end{array}$ \\
\hline Bremander, 2011 [6] & $\begin{array}{l}\text { Prospective cohort } \\
\text { (Sweden) }\end{array}$ & 935 & $\begin{array}{cl}\text { Standardized morbidity-rate ratio }(95 \% \mathrm{Cl}) \\
\text { - } & \text { IHD: } 2.20(1.77-2.70) \\
& \text { MI: } 1.32(0.81-2.04) \\
& \text { Hypertension: } 1.98(1.72-2.28) \\
& \text { DM: } 1.41(1.10-1.78) \\
& \text { Dyslipidemia: } 1.26(0.89-1.72)\end{array}$ \\
\hline
\end{tabular}

Abbreviations: $\mathrm{Cl}$ : Confidence Interval; IHD: Ischemic Heart Disease; CHF: Congestive Heart Failure; CVD: Cerebrovascular Disease; PVD: Peripheral Vascular Disease; DM: Diabetes Mellitus; MI: Myocardial Infarction

Table 1: Summary of studies on cardiovascular morbidity in Ankylosing Spondylitis in comparison with the general population.

in this group of patients [27]. Furthermore, a cohort study from Norway showed that mortality of AS patients could be independently predicted by increasing levels of C-reactive protein, delay in AS diagnosis, work disability and, additionally, infrequent use of NSAIDs, suggesting that the risks of NSAID treatment might be offset by the benefits of inflammation suppression [28]. On the other hand, for more than ten years, Tumor Necrosis Factor- $\alpha$ (TNF $\alpha$ ) blockers have offered a potent alternative for patients not responding or intolerant to NSAIDs [29]. Due to reports of increased morbidity and mortality in patients with advanced heart failure treated with TNFa antagonists [30], it is advocated that this class of drugs be prescribed with caution to patients with a history of heart failure. Apart from heart failure, though, several studies could not demonstrate an increased risk for cardiovascular disease with the use of TNFa blockers in RA, as well as across other indications [30,31]. On the contrary, in RA patients TNFa blockade has been associated with a reduction of cardiovascular events, an effect that has been attributed at least partly to the suppression of systemic inflammation rather than the modification of classical atherosclerosis risk factors [32-34]

Considerable evidence exists that classical atherosclerosis risk factors are impaired to a greater degree in AS patients compared to nonAS subjects. Regarding lifestyle factors it is possible that AS patients engage in less physical activity due to pain, disability or depression [35]. The issue of smoking in AS deserves special attention owing to several studies that have demonstrated that smoking is associated with higher disease activity, impaired function and worse radiographic damage [36,37]. Interestingly, a couple of recent studies of patients with early axial spondyloarthritis (regardless of fulfillment of the 1984 modified New York criteria for AS [38]) have also demonstrated that smoking status was associated with higher disease activity, poorer function, more severe inflammation on magnetic resonance imaging, as well as worse structural damage and progression $[39,40]$. Whether smoking is directly implicated in the pathophysiology of AS, as has been suggested for RA [41], remains to be elucidated; however the results of these studies imply that smoking may be twice as harmful to AS patients as non-AS subjects. Not only does it contribute to atherosclerosis and cardiovascular disease per se, but also, by enhancing inflammation and promoting structural damage (and consequently disability) limit physical function and further impair classical atherosclerosis risk factors.

Several other risk factors seem to be impaired in AS as well. Indeed, a meta-analysis has concluded that AS patients have significantly lower levels of the atheroprotective high density lipoprotein (HDL) cholesterol, as well as a higher prevalence of the metabolic syndrome [42]. In some studies, it has been further suggested that both lipid perturbation and the presence of the metabolic syndrome are related to AS disease activity $[43,44]$, while treatment with TNFa blockers seems to suppress insulin resistance, but has little, if any, effect on lipid levels $[45,46]$. Moreover, blood pressure levels have been found higher in AS patients [43], whereas hypertension and diabetes mellitus have been reported to also be more prevalent in AS compared to control subjects $[6,18]$. Additionally, a couple of novel atherosclerosis risk factors, such as homocysteine or asymmetric dimethylarginine, have been reported to be disturbed in AS $[47,48]$.

Several cross-sectional studies have investigated the issue of subclinical atherosclerosis in AS, with most evidence stemming from those assessing the carotid intima-media thickness (IMT) as a pertinent marker. A meta-analysis of studies assessing IMT in AS concluded that AS patients have significantly elevated IMT compared to controls [42] Interestingly, in some reports the IMT correlated not only with classical atherosclerosis risk factors, but also with various measures of AS, such as disease activity, function or metrology [49,50]. Furthermore, effective suppression of the inflammation in spondyloarthritides with anti-rheumatic treatment has been associated with improvements of vascular morphology and function [51,52].

Nevertheless, when interpreting the results of the studies on atherosclerosis and its risk factors in AS, it should be kept in mind that most of them have been cross-sectional, their sample size relatively small and none of them actually addressed prospectively "hard" outcomes, such as clinical cardiovascular disease. Publication bias should also be a concern, since studies failing to report significant results may also fail to reach publication. However, in the era of evidence-based medicine, decision-making ought to take into account the available evidence. Thus, despite the lack of high quality evidence, there seems to be an increased cardiovascular burden in AS patients due both to impaired 
classical risk factors, as well as to the inflammatory process itself, as seems to be the case with RA too [25] (Figure 1). Consequently, when managing patients with AS, the cardiovascular system should be screened not only for AS-specific cardiovascular complications, such as aortic insufficiency. Classical cardiovascular risk factors should also be considered given the possibility that cardiovascular disease may be more aggressive in this patient group than the general population and efforts should be undertaken to control these risk factors, as has already been recommended by the European League Against Rheumatism (EULAR) [53]. The treatment of risk factors may involve lifestyle modifications, such as smoking cessation, dietary interventions etc, as well as medical treatment, when appropriate. Importantly, the possible interaction between systemic inflammation and atherosclerosis attaches additional value to the effective control of AS-related inflammation, since it may not only benefit patients in terms of musculoskeletal symptoms and quality of life, but also act as an adjunct to the prevention of cardiovascular disease.

\section{References}

1. Papagoras C, Drosos AA (2011) Seronegative spondyloarthropathies: Evolving concepts regarding diagnosis and treatment. J Spine 1: 1-4.

2. Braun J, Sieper J (2007) Ankylosing spondylitis. Lancet 369: 1379-1390

3. Hermann KG, Baraliakos $X$, van der Heijde DM, Jurik AG, Landewé $R$, et al. (2012) Descriptions of spinal MRI lesions and definition of a positive MRI of the spine in axial spondyloarthritis: a consensual approach by the ASAS/ OMERACT MRI study group. Ann Rheum Dis 71: 1278-1288.

4. François RJ, Gardner DL, Degrave EJ, Bywaters EG (2000) Histopathologic evidence that sacroiliitis in ankylosing spondylitis is not merely enthesitis. Arthritis Rheum 43: 2011-2024.

5. D'Agostino MA, Olivieri I (2006) Enthesitis. Best Pract Res Clin Rheumatol 20: 473-486

6. Bremander A, Petersson IF, Bergman S, Englund M (2011) Population-based estimates of common comorbidities and cardiovascular disease in ankylosing spondylitis. Arthritis Care Res (Hoboken) 63: 550-556.

7. Zeboulon N, Dougados M, Gossec L (2008) Prevalence and characteristics of uveitis in the spondyloarthropathies: a systematic literature review. Ann Rheum Dis 67: 955-959.

8. Rudwaleit M, Baeten D (2006) Ankylosing spondylitis and bowel disease. Best Pract Res Clin Rheumatol 20: 451-471.

9. Lautermann D, Braun J (2002) Ankylosing spondylitis--cardiac manifestations. Clin Exp Rheumatol 20: S11-S15.

10. Bulkley BH, Roberts WC (1973) Ankylosing spondylitis and aortic regurgitation. Description of the characteristic cardiovascular lesion from study of eight necropsy patients. Circulation 48: 1014-1027.

11. Bergfeldt L, Edhag O, Vedin L, Vallin H (1982) Ankylosing spondylitis: an important cause of severe disturbances of the cardiac conduction system. Prevalence among 223 pacemaker-treated men. Am J Med 73: 187-191.

12. Bergfeldt L (1997) HLA-B27-associated cardiac disease. Ann Intern Med 127: 621-629.

13. Chatzikyriakidou A, Voulgari PV, Drosos AA (2011) What is the role of HLA-B27 in spondyloarthropathies? Autoimmun Rev 10: 464-468.

14. Dik VK, Peters MJ, Dijkmans PA, Van der Weijden MA, De Vries MK, et al. (2010) The relationship between disease-related characteristics and conduction disturbances in ankylosing spondylitis. Scand J Rheumatol 39: 38-41.

15. Lehtinen K (1993) Mortality and causes of death in 398 patients admitted to hospital with ankylosing spondylitis. Ann Rheum Dis 52: 174-176.

16. Zochling J, Braun J (2008) Mortality in ankylosing spondylitis. Clin Exp Rheumatol 26: S80-S84.

17. Prati C, Claudepierre P, Pham T, Wendling D (2011) Mortality in spondylarthritis. Joint Bone Spine 78: 466-470.

18. Han C, Robinson DW Jr, Hackett MV, Paramore LC, Fraeman KH, et al. (2006)
Cardiovascular disease and risk factors in patients with rheumatoid arthritis, psoriatic arthritis, and ankylosing spondylitis. J Rheumatol 33: 2167-2172.

19. Szabo SM, Levy AR, Rao SR, Kirbach SE, Lacaille D, et al. (2011) Increased risk of cardiovascular and cerebrovascular diseases in individuals with ankylosing spondylitis: a population-based study. Arthritis Rheum 63: 3294-3304.

20. Peters MJ, Visman I, Nielen MM, Van Dillen N, Verheij RA, et al. (2010) Ankylosing spondylitis: a risk factor for myocardial infarction? Ann Rheum Dis 69: 579-581.

21. Hollan I, Saatvedt K, Almdahl SM, Mikkelsen K, Moer R, et al. (2008) Spondyloarthritis: a strong predictor of early coronary artery bypass grafting. Scand J Rheumatol 37: 18-22.

22. Sokka T, Abelson B, Pincus T (2008) Mortality in rheumatoid arthritis: 2008 update. Clin Exp Rheumatol 26: S35-S61.

23. van Halm VP, Peters MJ, Voskuyl AE, Boers M, Lems WF, et al. (2009) Rheumatoid arthritis versus diabetes as a risk factor for cardiovascular disease: a cross-sectional study, the CARRE Investigation. Ann Rheum Dis 68: $1395-1400$.

24. Lindhardsen J, Ahlehoff O, Gislason GH, Madsen OR, Olesen JB, et al. (2011) The risk of myocardial infarction in rheumatoid arthritis and diabetes mellitus: a Danish nationwide cohort study. Ann Rheum Dis 70: 929-934.

25. John H, Toms TE, Kitas GD (2011) Rheumatoid arthritis: is it a coronary heart disease equivalent? Curr Opin Cardiol 26: 327-333.

26. Bolten WW (2006) Problem of the atherothrombotic potential of non-steroidal anti-inflammatory drugs. Ann Rheum Dis 65: 7-13.

27. Goodson NJ, Brookhart AM, Symmons DP, Silman AJ, Solomon DH (2009) Non-steroidal anti-inflammatory drug use does not appear to be associated with increased cardiovascular mortality in patients with inflammatory polyarthritis: results from a primary care based inception cohort of patients. Ann Rheum Dis 68: 367-372.

28. Bakland G, Gran JT, Nossent JC (2011) Increased mortality in ankylosing spondylitis is related to disease activity. Ann Rheum Dis 70: 1921-1925.

29. van der Heijde D, Sieper J, Maksymowych WP, Dougados M, Burgos-Vargas R, et al. (2011) 2010 Update of the international ASAS recommendations for the use of anti-TNF agents in patients with axial spondyloarthritis. Ann Rheum Dis 70: $905-908$.

30. Furst DE, Keystone EC, Braun J, Breedveld FC, Burmester GR, et al. (2012) Updated consensus statement on biological agents for the treatment of rheumatic diseases, 2011. Ann Rheum Dis 71: i2-i45.

31. Burmester GR, Panaccione R, Gordon KB, Mcllraith MJ, Lacerda AP (2012) Adalimumab: long-term safety in 23458 patients from global clinical trials in rheumatoid arthritis, juvenile idiopathic arthritis, ankylosing spondylitis, psoriatic arthritis, psoriasis and Crohn's disease. Ann Rheum Dis.

32. Barnabe C, Martin BJ, Ghali WA (2011) Systematic review and meta-analysis: anti-tumor necrosis factor $\alpha$ therapy and cardiovascular events in rheumatoid arthritis. Arthritis Care Res (Hoboken) 63: 522-529.

33. Dixon WG, Watson KD, Lunt M, Hyrich KL, Silman AJ, et al. (2007) Reduction in the incidence of myocardial infarction in patients with rheumatoid arthritis who respond to anti-tumor necrosis factor alpha therapy: results from the British Society for Rheumatology Biologics Register. Arthritis Rheum 56: 2905-2912.

34. Daïen CI, Duny Y, Barnetche T, Daurès JP, Combe B, et al. (2012) Effect of TNF inhibitors on lipid profile in rheumatoid arthritis: a systematic review with meta-analysis. Ann Rheum Dis 71: 862-868.

35. Peters MJ, van der Horst-Bruinsma IE, Dijkmans BA, Nurmohamed MT (2004) Cardiovascular risk profile of patients with spondylarthropathies, particularly ankylosing spondylitis and psoriatic arthritis. Semin Arthritis Rheum 34: 585592.

36. Kaan U, Ferda O (2005) Evaluation of clinical activity and functional impairment in smokers with ankylosing spondylitis. Rheumatol Int 25: 357-360.

37. Ward MM, Hendrey MR, Malley JD, Learch TJ, Davis JC Jr, et al. (2009) Clinical and immunogenetic prognostic factors for radiographic severity in ankylosing spondylitis. Arthritis Rheum 61: 859-866.

38. van der Linden S, Valkenburg HA, Cats A (1984) Evaluation of diagnostic criteria for ankylosing spondylitis. A proposal for modification of the New York criteria. Arthritis Rheum 27: 361-368.

39. Poddubnyy D, Haibel H, Listing J, Märker-Hermann E, Zeidler H, et al. (2012) 
Baseline radiographic damage, elevated acute-phase reactant levels, and cigarette smoking status predict spinal radiographic progression in early axial spondylarthritis. Arthritis Rheum 64: 1388-1398.

40. Chung HY, Machado P, van der Heijde D, D’Agostino MA, Dougados M (2012) Smokers in early axial spondyloarthritis have earlier disease onset, more disease activity, inflammation and damage, and poorer function and healthrelated quality of life: results from the DESIR cohort. Ann Rheum Dis 71: 809 816.

41. Baka Z, Buzás E, Nagy G (2009) Rheumatoid arthritis and smoking: putting the pieces together. Arthritis Res Ther 11: 238

42. Mathieu S, Gossec L, Dougados M, Soubrier M (2011) Cardiovascular profile in ankylosing spondylitis: a systematic review and meta-analysis. Arthritis Care Res (Hoboken) 63: 557-563.

43. Papadakis JA, Sidiropoulos PI, Karvounaris SA, Vrentzos GE, Spanakis EK et al. (2009) High prevalence of metabolic syndrome and cardiovascular risk factors in men with ankylosing spondylitis on anti-TNFalpha treatment: correlation with disease activity. Clin Exp Rheumatol 27: 292-298.

44. van Halm VP, van Denderen JC, Peters MJ, Twisk JW, van der Paardt M, et al. (2006) Increased disease activity is associated with a deteriorated lipid profile in patients with ankylosing spondylitis. Ann Rheum Dis 65: 1473-1477.

45. Kiortsis DN, Mavridis AK, Vasakos S, Nikas SN, Drosos AA (2005) Effects of infliximab treatment on insulin resistance in patients with rheumatoid arthritis and ankylosing spondylitis. Ann Rheum Dis 64: 765-766.

46. Kiortsis DN, Mavridis AK, Filippatos TD, Vasakos S, Nikas SN, et al. (2006) Effects of infliximab treatment on lipoprotein profile in patients with rheumatoid arthritis and ankylosing spondylitis. J Rheumatol 33: 921-923.
47. Gonzalez-Lopez L, Sanchez-Hernandez JD, Aguilar-Chavez EA, Cota-Sanchez AR, Lopez-Olivo MA, et al. (2008) Hyperhomocysteinemia in ankylosing spondylitis: prevalence and association with clinical variables. Rheumatol Int 28: $1223-1228$

48. Kemény-Beke Á, Gesztelyi R, Bodnár N, Zsuga J, Kerekes G, et al. (2011) Increased production of asymmetric dimethylarginine (ADMA) in ankylosing spondylitis: association with other clinical and laboratory parameters. Joint Bone Spine 78: 184-187.

49. Hamdi W, Chelli Bouaziz M, Zouch I, Ghannouchi MM, Haouel M, et al. (2012) Assessment of preclinical atherosclerosis in patients with ankylosing spondylitis. J Rheumatol 39: 322-326.

50. Bodnár N, Kerekes G, Seres I, Paragh G, Kappelmayer J, et al. (2011) Assessment of subclinical vascular disease associated with ankylosing spondylitis. J Rheumatol 38: 723-729.

51. Tam LS, Li EK, Shang Q, Tomlinson B, Li M, et al. (2011) Tumour necrosis factor alpha blockade is associated with sustained regression of carotid intimamedia thickness for patients with active psoriatic arthritis: a 2-year pilot study. Ann Rheum Dis 70: 705-706.

52. van Eijk IC, Peters MJ, Serné EH, van der Horst-Bruinsma IE, Dijkmans BA et al. (2009) Microvascular function is impaired in ankylosing spondylitis and improves after tumour necrosis factor alpha blockade. Ann Rheum Dis 68: 362 366.

53. Peters MJ, Symmons DP, McCarey D, Dijkmans BA, Nicola $P$, et al. (2010) EULAR evidence-based recommendations for cardiovascular risk management in patients with rheumatoid arthritis and other forms of inflammatory arthritis Ann Rheum Dis 69: 325-331. 